\title{
The association of long-term calcium and dairy products intake in adolescence with carotid intima media thickness and metabolic syndrome in early adulthood: Tehran Lipid and Glucose Study
}

\section{Assa AkbarySedigh}

Nutrition and Endocrine Research Center, Research Institute for Endocrine Sciences, Shahid Beheshti University of Medical Sciences, Tehran, Iran

\section{Golaleh Asghari}

Department of Clinical Nutrition and Dietetics, Faculty of Nutrition Sciences and Food Technology, Shahid Beheshti University of Medical Sciences, Tehran, Iran

\section{Maryam Mahdavi}

Obesity Research Center, Research Institute for Endocrine Sciences, Shahid Beheshti University of

Medical Sciences, Tehran, Iran

Parvin Mirmiran ( $D$ mirmiran@endocrine.ac.ir)

Shahid Beheshti University of Medical Sciences https://orcid.org/0000-0003-2391-4924

\section{Fereidoun Azizi}

Endocrine Research Center, Research Institute for Endocrine Sciences, Shahid Beheshti University of Medical Sciences, Tehran, Iran

\section{Research}

Keywords: calcium, dairy, cIMT, metabolic syndrome, adolescence, early adulthood

Posted Date: February 10th, 2022

DOI: https://doi.org/10.21203/rs.3.rs-1296806/v1

License: (c) (1) This work is licensed under a Creative Commons Attribution 4.0 International License. Read Full License 


\section{Abstract}

Background: Calcium could impact on vascular functions and structures and cause atherosclerosis. Thus, we aimed to examine the association of long-term calcium and dairy products intake in adolescence with cIMT and MetS in early adulthood.

Methods: We considered 217 adolescents aged 12-18 years in the frame work of the Tehran Lipid and Glucose Study (2006-2009) and follow-up them to early adulthood (2015-2017). The valid food frequency questionnaire was used to assess dietary intake. Ultrasound examination was used to measure common carotid artery. The joint interim statement and cook et al criteria were used for adults and adolescents to consider MetS, respectively.

Results: Adolescents' average calcium intake from dairy and non-dairy sources were $395 \mathrm{mg} / \mathrm{d}$ and 1088 $\mathrm{mg} / \mathrm{d}$, respectively while adults had $212 \mathrm{mg} / \mathrm{d}$ and $1191 \mathrm{mg} / \mathrm{d}$. In addition, the mean of cIMT in adults was $0.54 \mathrm{~mm}$. There was no relationship of non-dairy $(\beta$ : $-0.03 ; P=0.804)$, and total calcium ( $\beta$ : -0.001 ; $P=0.591)$ intake with cIMT and TG. None of the dairy products had link with cIMT, MetS and its components, except cream with cIMT after full adjustment of potential confounders ( $\beta: 0.245 ; P=0.009)$. Also, we found that the intake of non-dairy products could increase DBP after controlling for potential confounders $(\beta: 0.365 ; P=0.012)$. Adolescence with higher quartiles of total calcium intake had no odds ratio of MetS in early adulthood $(\beta: 2.05, P=0.371)$.

Conclusions: Adolescence calcium and dairy products intake, with the exception of cream did not increase early adulthood cIMT and MetS and its components.

\section{Introduction}

Cardiovascular disease (CVD) which is one of the major concerns and causes of death all over the world in the last few decades, develops in a prolonged period of time, and stems from unhealthy dietary patterns as well as sedentary lifestyle (1). Also, it could happen after increasing of carotid intima media thickness (cIMT), metabolic syndrome, and atherosclerosis (2-4). Hence, the early diagnosis of these triggers in addition to modifications of food habits are the prominent approach to prevent the chronic and dangerous symptoms and CVD.

Eating habits and nutrients have an effective role in incidence of metabolic syndrome and atherosclerosis in a long-life time (5-9). Particularly, calcium has been claimed to impact on vascular functions and structures in the way to contract myocardium, the muscle of heart and also coagulate blood (10). Needless to say that dairy products providing calcium requirements are not exceptional. In a double-blind randomized trial study, women were given calcium supplementation with 2-year duration and the results showed that there was a significant increment in cholesterol levels and cIMT in postmenopausal women (11). whereas, long-term dietary calcium intake from childhood to adulthood was not associated with any cardiovascular risk including clMT, arterial pulse wave velocity (PWV), and stiffness index (12). In terms of dairy products, some review studies concluded that CVD could be positively or impartially influenced 
by dairy intake, especially yoghurt, kefir and cheese (13-15). However, some evidence claimed that high consumption of calcium might have detrimental effects on CVD (16-18). Therefore, there are some controversies and inconsistency of findings needing to become more clear by further research and studies.

To the best of our knowledge, the long-term relationship between calcium and dairy products with CVD risks from childhood and adolescence to young adulthood has not been examined yet. Thus, the present study was conducted to clarify if there is a negative or positive impact on vascular structure and metabolic syndrome by calcium intake from dairy and non-dairy after eight years.

\section{Methods And Materials}

\section{Population of the study}

The present study has been conducted in the frame work of Tehran Lipid and Glucose Study (TLGS) in the district 13 of Tehran since 1999. The details have been previously released (19). The participants in the cohort study were followed up every three years. The dietary assessments were carried out in third survey (2006-2009) that is why we considered 217 adolescents and young adults aged 12-18 years in this period of time. Measured cIMT was related to survey six (2015-2017) in early adulthood. Thus, these two periods of the study were considered to examine the changes after 10-year median follow- up. Exclusion criteria including age under 12 in survey three and under 19 in survey six, both age groups who had any disease such as cardiovascular, kidney, and liver diseases, had any kind of drugs intake, went on a specific diet, and any of participants who had missing data on Food Frequency Questionnaire (FFQ), CIMT, and one of the factors of metabolic syndrome were taken into account. All participants were given to sign the written consent to take a part. The ethics research council of the Research Institute for Endocrine Sciences, Shahid Beheshti University of Medical Sciences consented the protocol of this study.

\section{Dietary intake and Physical Activity Assessment}

The valid and reliable FFQ was used to assess dietary intakes (20). The participants were asked about 168 food items and the consumption frequency over the past year on a daily, weekly, and monthly basis during face-to-face interview. Household measures were taken into account for portion sizes and then converted to grams. The food composition table (FCT) of the United States Department of Agriculture (USDA) was used to evaluate energy and nutrients. The Iranian FCT was considered for local foods that were not existed in USDA FCT. In addition, both adolescents and adults answered questions about their leisure and daily activities by Modifiable Activity Questionnaire (MAQ) and Lipid Research Clinics (LRC) questionnaire $(21,22)$.

\section{Anthropometric and clinical Measurements}

Participants were interviewed to collect information about demographic, medical history and smoking status. Height and weight were assessed by a digital scale and an elastic tape with light clothing and 
without shoes in the standard position. Waist circumference (WC) was recorded at the umbilicus (23). Body Mass index (BMI) was calculated as weight $(\mathrm{Kg})$ divided by the square of height $\left(\mathrm{m}^{2}\right)$.

After 12-14 hours overnight fasting, blood samples were drawn into vacutainer tubes to measure total cholesterol, triglyceride, high-density lipoprotein (HDL), low-density lipoprotein (LDL), fasting blood sugar (FBS) between 7:00 to 9:00 am. Moreover, their systolic and diastolic blood pressure (SBP, DBP) were measured by a mercury sphygmomanometer and Korotkoff sound technique by an experienced physician after 15 minutes resting.

\section{Carotid intima-media thickness}

Ultrasound examination of the subjects was done with a linear 7.5-10 MHz transducer (Samsung Medison SonoAceR3 ultrasound machine). Participants in the supine position with the neck extended and slightly rotated to the opposite side of examination. The measurements were performed on both left and right carotids. The decision on using the left common carotid artery (LCCA) was based on previous published articles in the literature (24). Initial carotid scan was performed in the transverse plane throughout the course of the artery to evaluate the subject's anatomy, locate atherosclerotic plaques (if there were any) and determine the site of maximal wall thickening in the near or far wall. Then longitudinal scans of the artery with different angles were performed. Measurements were done in plaque-free arterial segments which also fulfilled the criteria of optimal B-mode imaging as described below. cIMT was done manually as a hypo echoic band between the echogenic intimal and adventitial surfaces of the arterial wall. The distance between the leading edge of the first and second echogenic lines of the far walls of the distal segment of the common carotid artery on both sides was measured in three locations with the average as the final measurement of that side. The cIMT of carotid bulb and the internal carotid artery on both sides were sporadically measured in patients that fulfilled the criteria of optimal technique and image. To assess the reliability agreement, cIMT was measured by two radiologists in a subsample of 30 individuals ( $66.7 \%$ female) with mean age and BMI of 41.7 years and $24.4 \mathrm{~kg} / \mathrm{m}^{2}$, respectively. The degree of cIMT measures agreement between the two radiologists was evaluated by using an interclass correlation coefficient (ICC). ICC estimates and the $95 \%$ confident intervals were calculated using SPSS version 20 based on 2-way mixed-effects model and reported ICC results as ICC $=0.79$ with $95 \%$ confident interval $=0.55-0.90$. The ICC is a value between 0 and 1 , where values between 0.75 and 0.9 indicates good reliability (25).

\section{Metabolic syndrome}

For adolescents, we used the definition provided by cook et al due to no universal definition exists (26). Metabolic syndrome (MetS) has been defined as 3 or more of the following factors: fasting triglyceride (TG) $\geq 110 \mathrm{mg} / \mathrm{dL}, \mathrm{HDL}-\mathrm{C}<40 \mathrm{mg} / \mathrm{dL}, \mathrm{WC} \geq 90$ percentile for age and sex, based on national reference curves (27), systolic blood pressure and/or diastolic blood pressure $\geq 90$ percentile for age, sex, and height, in terms of National Heart, Lung, and Blood Institute's recommended cut-off points (28), and FBS $\geq 100 \mathrm{mg} / \mathrm{dL}$, as stated by the recent recommendation of American Diabetes Association (29). Regarding the joint interim statement (JIS) criteria in adults, it defines MetS as $\geq 3$ features including 
(30): WC $\geq 91 \mathrm{~cm}$ for women and $\geq 89 \mathrm{~cm}$ for men based on population- and country- specific cut- off point for Iranians (31), fasting plasma glucose $\geq 100 \mathrm{mg} / \mathrm{dL}$ or drug treatment, $\mathrm{TG} \geq 150 \mathrm{mg} / \mathrm{dL}$ or drug treatment, $\mathrm{HDL}-\mathrm{C}<50 \mathrm{mg} / \mathrm{dL}$ for women and $<40 \mathrm{mg} / \mathrm{dL}$ for men or drug treatment, and escalated blood pressure was defined as systolic blood pressure $\geq 130 \mathrm{~mm} \mathrm{Hg}$, diastolic blood pressure $\geq 85 \mathrm{~mm} \mathrm{Hg}$ or antihypertensive drug treatment.

\section{Statistical Analysis}

Kolmograph - Smirnov test and histogram was used to determine the normal distribution of the data. Continuous and categorical variables reported by mean \pm SD for normal and median (25th -75 th percentiles) for skewed variables. Differences in anthropometric and clinical characteristics in adolescence and adulthood were tested using the paired t-test, Wilcoxon and McNemar test for normal, skewed, and categorical variables, respectively. Linear regression was used to investigate the association of adolescence dairy, non-dairy, and total calcium intake with cIMT, and MetS components in early adulthood. Binary logistic regression was used to examine the MetS of adulthood across quartiles of calcium and dairy intake in adolescence. We also considered potential confounding factors such as age, sex, BMI, physical activity, energy intake, smoking and family history of CVD in all analysis. In the current study, SPSS software version 20 (Chicago, IL, United State) was used for data analysis. P-value $<0.05$ was considered statistically significant.

\section{Results}

In the current study, as Table 1 shows the anthropometric and clinical measurements in adolescence and adulthood, the mean age of adolescents and adults were 14.9 years old and 24.9 years old, respectively. Also, the averages of BMI were $23.1 \mathrm{~kg} / \mathrm{m}^{2}$ and $25.6 \mathrm{~kg} / \mathrm{m}^{2}$ in the adolescents and adults. Adolescents' average calcium intake from sources of dairy and non-dairy were $395 \mathrm{mg} / \mathrm{d}$ and $1088 \mathrm{mg} / \mathrm{d}$ while adults had $212 \mathrm{mg} / \mathrm{d}$ and $1191 \mathrm{mg} / \mathrm{d}$. In addition, the mean of cIMT in adults was $0.54 \mathrm{~mm}$. The number of adolescents and adults with MetS were 27 and 22, respectively. All components of MetS had difference between adolescence and adulthood $(P<0.001)$ except TG $(P: 805)$ as well as non-dairy intake (P:0.060). The mean of total calcium intake decreased from adolescence $(1484 \mathrm{mg} / \mathrm{d})$ to adulthood $(1403 \mathrm{mg} / \mathrm{d})$ while, the mean of HDL-C, SBP and DBP, and WC increased after 10 years $(P<0.001)$. 
Table 1

Anthropometric and clinical measurements in adolescence and adulthood.

\begin{tabular}{|c|c|c|c|}
\hline Variables & Adolescence & Adulthood & P-Value \\
\hline Age (year) & $14.9 \pm 2.1$ & $24.9 \pm 2.9$ & $<0.001$ \\
\hline $\mathrm{BMI}\left(\mathrm{kg} / \mathrm{m}^{2}\right)$ & $23.1 \pm 4.3$ & $25.6 \pm 4.7$ & $<0.001$ \\
\hline Dairy $(\mathrm{mg} / \mathrm{d})$ & $395 \pm 573$ & $212 \pm 165$ & $<0.001$ \\
\hline Non-Dairy (mg/d) & $1088 \pm 574$ & $1191 \pm 473$ & 0.060 \\
\hline Total calcium $(\mathrm{mg} / \mathrm{d})$ & $1484 \pm 982$ & $1403 \pm 568$ & 0.337 \\
\hline Energy intake (Kcal/d) & $2693 \pm 1087$ & $2440 \pm 871$ & 0.005 \\
\hline Physical activity (MET/h) & $536(259-1488)$ & $496(246-1127)$ & 0.035 \\
\hline a Smokers, n (\%) & $50(24.4)$ & $32(14.7)$ & 0.127 \\
\hline LDL-C (mgl/dl) & $86.6 \pm 23.5$ & $96.1 \pm 26.2$ & $<0.001$ \\
\hline Cholesterol (mg/dl) & $152.9 \pm 28.4$ & $165.9 \pm 31.5$ & $<0.001$ \\
\hline HDL-C (mgl/dl) & $45.3 \pm 10.0$ & $48.7 \pm 10.3$ & $<0.001$ \\
\hline TG (mg/dl) & $86.5(65.0-120.0)$ & $86.5(66.2-126.0)$ & 0.805 \\
\hline FBS $(\mathrm{mg} / \mathrm{dl})$ & $87.6 \pm 8.5$ & $87.4 \pm 7.9$ & 0.004 \\
\hline $\mathrm{SBP}(\mathrm{mmHg})$ & $102.2 \pm 11.0$ & $107.0 \pm 11.4$ & $<0.001$ \\
\hline $\mathrm{DBP}(\mathrm{mmHg})$ & $66.4 \pm 9.3$ & $71.8 \pm 8.9$ & $<0.001$ \\
\hline Waist circumference $(\mathrm{cm})$ & $78.4 \pm 11.9$ & $86.8 \pm 12.2$ & $<0.001$ \\
\hline clMT (mm) & - & 0.54 & - \\
\hline Metabolic Syndrome, n (\%) & $27(12.4)$ & $22(10.1)$ & $>0.999$ \\
\hline \multicolumn{4}{|c|}{$\begin{array}{l}\text { Abbreviations: BMI, body mass index; cIMT, carotid intima media thickness; DBP, diastolic blood } \\
\text { pressure; FBS, fasting blood sugar; HDL-C, high density lipoprotein-cholesterol; LDL, low density } \\
\text { lipoprotein-cholesterol; SBP, systolic blood pressure; TG, triglyceride. }\end{array}$} \\
\hline \multicolumn{4}{|c|}{$\begin{array}{l}\text { Using the paired t-test, Wilcoxon and McNemar test for normal, skewed, and categorical variables, } \\
\text { respectively. }\end{array}$} \\
\hline P-value $<0.05$ significant. & & & \\
\hline
\end{tabular}

Table 2 presents the associations of adolescence dairy, non-dairy, and total calcium intake with clMT, and MetS components in early adulthood. There were no relationships of dairy $(\beta: 0.041 ; 95 \% \mathrm{Cl}: 0.000,0.000$; P:0.647), non-dairy ( $\beta: 0.006 ; 95 \% \mathrm{Cl}: 0.000,0.000 ; \mathrm{P}: 0.946)$ and total calcium ( $\beta: 0.029 ; 95 \% \mathrm{Cl}: 0.000$, 0.000; P:0.752) intake with TG after controlling for age, sex, BMI, and physical activity. While, after further 
adjusting energy intake, smoking, and family history of cardiovascular disease, we observed the associations of non-dairy ( $\beta: 0.274 ; 95 \% \mathrm{Cl}: 0.000,0.000 ; \mathrm{P}: 0.046)$ and total calcium intake ( $\beta: 0.275$; $95 \% \mathrm{Cl}: 0.000,0.000 ; \mathrm{P}: 0.039)$ with TG but not with dairy intake ( $\beta: 0.133 ; 95 \% \mathrm{Cl}: 0.000,0.000 ; \mathrm{P}: 0.205)$. Moreover, we found that the intake of non-dairy calcium could increase DBP after adjusting for the potential confounders ( $\beta: 0.365 ; 95 \% \mathrm{Cl}: 0.001,0.010 ; \mathrm{P}: 0.012)$. However, there were not any association of dairy, non-dairy, and total calcium intake with cIMT and other components of MetS including HDL-C, FBS, SBP, and WC. 
Table 2

Associations (, $95 \% \mathrm{Cl}$ ) of adolescence dairy, non-dairy, and total calcium intake with cIMT, and MetS components in early adulthood.

\begin{tabular}{|c|c|c|c|c|c|c|c|}
\hline$\beta$ & & & & & & & \\
\hline Outcomes & & $\begin{array}{l}\text { Non-Dairy } \\
\text { Calcium }\end{array}$ & $\begin{array}{l}\mathrm{P}- \\
\text { value }\end{array}$ & $\begin{array}{l}\text { Dairy } \\
\text { Calcium }\end{array}$ & $\begin{array}{l}\text { P- } \\
\text { Value }\end{array}$ & $\begin{array}{l}\text { Total } \\
\text { calcium }\end{array}$ & $\begin{array}{l}\text { P- } \\
\text { Value }\end{array}$ \\
\hline clMT (mm) & Model & $\begin{array}{l}-0.03(0.000 \\
0.000)\end{array}$ & 0.800 & $\begin{array}{l}-0.07 \\
0.000\end{array}$ & & $\begin{array}{l}-0.001 \\
(0.000\end{array}$ & 0.988 \\
\hline & & & 0.804 & $0.000)$ & 0.607 & $0.000)$ & 0.591 \\
\hline & $\begin{array}{l}\text { Model } \\
2\end{array}$ & $, 0.000)$ & & $\begin{array}{l}-0.05 \\
(0.000 \\
0.000)\end{array}$ & & $\begin{array}{l}-0.07 \\
(0.000 \\
0.000)\end{array}$ & \\
\hline HDL-C (mmol/l) & Model & -0.151 & 0.078 & -0.086 & 0.350 & -0.142 & 0.119 \\
\hline & 1 & $\begin{array}{l}(-0.005) \\
0.000)\end{array}$ & 0.901 & $\begin{array}{l}(-0.001, \\
0.001)\end{array}$ & 0.740 & $\begin{array}{l}(-0.003) \\
0.000)\end{array}$ & 0.848 \\
\hline & $\begin{array}{l}\text { Mlodel } \\
2\end{array}$ & $\begin{array}{l}-0.017 \\
(-0.004 \\
0.004)\end{array}$ & & $\begin{array}{l}0.034 \\
(-0.002, \\
0.003)\end{array}$ & & $\begin{array}{l}0.025 \\
(-0.002 \\
0.002)\end{array}$ & \\
\hline TG $(\mathrm{mmol} / \mathrm{l})$ & Model & 0.006 (0.000, & 0.946 & 0.041 & 0.647 & 0.029 & 0.752 \\
\hline & & & 0.046 & $0.000)^{\prime}$ & 0.205 & $0.000)^{\prime}$ & 0.039 \\
\hline & $\begin{array}{l}\text { Model } \\
2\end{array}$ & $\begin{array}{l}0.274(0.000, \\
0.000)\end{array}$ & & $\begin{array}{l}0.133 \\
(0.000 \\
0.000)\end{array}$ & & $\begin{array}{l}0.275 \\
(0.000 \\
0.000)\end{array}$ & \\
\hline FBS $(\mathrm{mmol} / \mathrm{l})$ & Model & 0.148 (0.000, & 0.108 & 0.104 & 0.268 & 0.148 & 0.114 \\
\hline & & & 0.212 & $0.003)$ & 0.487 & $0.002)^{\prime}$ & 0.226 \\
\hline & $\begin{array}{l}\text { Model } \\
2\end{array}$ & $\begin{array}{l}0.177(0.001 \\
0.006)\end{array}$ & & $\begin{array}{l}0.075 \\
(-0.002 \\
0.003)\end{array}$ & & $\begin{array}{l}0.167 \\
(-0.001 \\
0.003)\end{array}$ & \\
\hline $\mathrm{SBP}(\mathrm{mmHg})$ & Model & -0.022 & 0.809 & -0.162 & 0.078 & -0.111 & 0.230 \\
\hline & & $0.003)$ & 0.552 & $0.000)$ & 0.170 & $0.001)$ & 0.456 \\
\hline & 2 & $\begin{array}{l}0.084(-0.004 \\
0.007)\end{array}$ & & $\begin{array}{l}-0.147 \\
(-0.006 \\
0.001)\end{array}$ & & $\begin{array}{l}-0.103 \\
(-0.004 \\
0.002)\end{array}$ & \\
\hline $\mathrm{DBP}(\mathrm{mmHg})$ & Model & $0.212(0.000$ & 0.022 & $\begin{array}{l}0.091 \\
(-0001\end{array}$ & 0.342 & $\begin{array}{l}0.177 \\
0000\end{array}$ & 0.063 \\
\hline & & & 0.012 & $0.004)^{\prime}$ & 0.499 & $0.003)$ & 0.062 \\
\hline & 2 & $0.010)$ & & $\begin{array}{l}0.076 \\
(-0.002 \\
0.004)\end{array}$ & & $\begin{array}{l}0.266 \\
(0.000 \\
0.004)\end{array}$ & \\
\hline
\end{tabular}




\begin{tabular}{|c|c|c|c|c|c|c|c|}
\hline \multicolumn{8}{|l|}{$\beta$} \\
\hline \multirow{3}{*}{$\begin{array}{l}\text { Waist } \\
\text { Circumference } \\
(\mathrm{cm})\end{array}$} & $\begin{array}{l}\text { Model } \\
1\end{array}$ & $\begin{array}{l}0.104(-0.001 \\
0.005)\end{array}$ & \multirow{3}{*}{$\begin{array}{l}0.130 \\
0.148\end{array}$} & \multirow{2}{*}{$\begin{array}{l}0.073 \\
(-0.001 \\
0.004)\end{array}$} & \multirow{3}{*}{$\begin{array}{l}0.296 \\
0.584\end{array}$} & \multirow{2}{*}{$\begin{array}{l}0.104 \\
(0.000 \\
0.003)\end{array}$} & \multirow{3}{*}{$\begin{array}{l}0.136 \\
0.229\end{array}$} \\
\hline & \multirow{2}{*}{$\begin{array}{l}\text { Model } \\
2\end{array}$} & \multirow{2}{*}{$\begin{array}{l}0.152(-0.001 \\
0.007)\end{array}$} & & & & & \\
\hline & & & & $\begin{array}{l}0.044 \\
(-0.002 \\
0.004)\end{array}$ & & $\begin{array}{l}0.123 \\
(-0.001 \\
0.004)\end{array}$ & \\
\hline \multicolumn{8}{|c|}{$\begin{array}{l}\text { Abbreviations: cIMT, carotid intima media thickness; DBP, diastolic blood pressure; FBS, fasting blood } \\
\text { sugar; HDL-C, high density lipoprotein-cholesterol; SBP, systolic blood pressure; TG, triglyceride. }\end{array}$} \\
\hline \multicolumn{8}{|c|}{ Model 1. Adjusted for age, sex, body mass index, and physical activity. } \\
\hline \multicolumn{8}{|c|}{ Model 2. Adjusted for Model 1 and energy intake, smoking, family history of cardiovascular disease. } \\
\hline \multicolumn{8}{|c|}{ Using Linear regression test. } \\
\hline \multicolumn{8}{|c|}{ P-value $<0.05$ significant. } \\
\hline
\end{tabular}

Table 3 indicates the associations of adolescence dairy and non-dairy calcium intake with odds ratio of MetS in early adulthood. We found that adolescents with higher quartiles of calcium intake had higher odds ratio of MetS in early adulthood in comparison with first quartile after controlling for potential confounders; however, it was not statistically significant (OR: $2.05 ; 95 \% \mathrm{Cl}: 0.12,35.17$; P:0.371).

Table 3

Associations of adolescence total calcium intake with odds ratio of MetS in early adulthood.

\begin{tabular}{|c|c|c|c|c|c|c|}
\hline Outcomes & & Q1 & Q2 & Q3 & Q4 & $\begin{array}{l}\text { P- } \\
\text { Value }\end{array}$ \\
\hline \multirow[t]{2}{*}{$\begin{array}{l}\text { Metabolic } \\
\text { Syndrome }\end{array}$} & $\begin{array}{l}\text { Model } \\
1\end{array}$ & \multirow{2}{*}{$\begin{array}{l}1 \\
1\end{array}$} & $\begin{array}{l}1.81(0.26- \\
12.46)\end{array}$ & $\begin{array}{l}2.87(0.50- \\
16.54)\end{array}$ & $\begin{array}{l}1.79(0.25- \\
12.66)\end{array}$ & \multirow{2}{*}{$\begin{array}{l}0.443 \\
0.371\end{array}$} \\
\hline & $\begin{array}{l}\text { Model } \\
2\end{array}$ & & $\begin{array}{l}1.35(0.16- \\
10.99)\end{array}$ & $\begin{array}{l}2.70(0.38- \\
18.84)\end{array}$ & $\begin{array}{l}2.05(0.12- \\
35.17)\end{array}$ & \\
\hline \multicolumn{7}{|c|}{ Abbreviation: MetS, metabolic Syndrome. } \\
\hline \multicolumn{7}{|c|}{ Model 1. Adjusted for age, sex, body mass index, and physical activity. } \\
\hline \multicolumn{7}{|c|}{ Model 2. Adjusted for Model 1 and energy intake, smoking, family history of cardiovascular disease. } \\
\hline \multicolumn{7}{|c|}{ Using Binary logistic regression test. } \\
\hline \multicolumn{7}{|c|}{ P-value $<0.05$ significant. } \\
\hline
\end{tabular}

Noteworthy, as Supplement 1 shows the associations of adolescence dairy products intake with cIMT in early adulthood, it was observed that between dairy products, only the intake of cream could increase cIMT in early adults after 10 years (OR:0.245; 95\%Cl:0.001, 0.009; P:0.009). Moreover, Supplement 2 displays the associations of adolescence dairy products intake with components of MetS in early 
adulthood. In this regard, higher skim milk consumption increased TG (OR: 0.189; 95\%Cl: 0.000, 0.001; P:0.038) and DBP (OR: $0.212 ; 95 \% \mathrm{Cl}: 0.002,0.031 ; \mathrm{P}: 0.029)$ whereas plain yoghurt (OR: $-0.193 ; 95 \% \mathrm{Cl}$ : $-0.048,-0.001 ; \mathrm{P}: 0.039)$ and butter decreased SBP (OR: $-0.211 ; 95 \% \mathrm{Cl}:-0.092,-0.006 ; \mathrm{P} ; 0.027)$. In addition, the intake of plain ice cream had reverse association with WC after full adjustment with confounding factors (OR: $-0.166 ; 95 \% \mathrm{Cl}:-0.250,-0.024 ; \mathrm{P}: 0.018)$. Negative relationship between butter and DBP was also found (OR: $-0.199 ; 95 \% \mathrm{Cl}:-0.071,-0.001 ; \mathrm{P}: 0.045)$.

\section{Discussion}

In the current study, we found no association of adolescence total calcium, dairy and non-dairy calcium intake with early adulthood cIMT. However, adolescents with the intake of cream had increased cIMT in their early adulthood. Furthermore, no higher MetS in the early adulthood was observed in the adolescents with higher consumption of dairy and non-dairy calcium. Moreover, skim milk, non-dairy and total calcium intake, but not other dairy products, could increase TG. The intake of plain ice cream showed reverse association with WC after 10-year follow-up in young adults.

There are some studies examining the calcium and dairy products intake in childhood and its association with cardiovascular risk factors in adulthood $(10,12,17,32-35)$. Similar to our findings, the research conducted by Wu et al in 3-18 years old participants concluded that there were not any linear and nonlinear relationships between long term dietary calcium intake with cIMT, PWV, stiffness index, carotid artery compliance, and Young's elastic modulus (12). In terms of dairy products, although we could observe the relationship between long-term intake of cream and elevated cIMT, another research found no significant linkage between childhood dairy intake with adulthood coronary heart disease (CHD) and stroke mortality, while they observed that $400 \mathrm{mg} / \mathrm{d}$ calcium consumption had an association with decreased $40-60 \%$ stroke mortality (32). Interestingly, a U-shaped association in 20-year longitudinal study in China was seen between calcium intake of adolescents and hypertension in adults. Meaning that lower and higher intake of calcium in adolescence can cause high blood pressure in later life (33). We demonstrated that the consumption of plain yoghurt and butter can decrease SBP and DBP. Concerning another CVD risk factor, an evidence found no relationship between long-term calcium intake in youth with risk of type 2 diabetes in adulthood (34). Whereas, high school adolescents with dairy product intake demonstrated $38 \%$ lower risk of type 2 diabetes in middle-aged women (35). According to some other surveys claimed that there might be detrimental impact of calcium supplementation on CVD in adults (10, 17), all above mentioned studies did not indicate the harmful influence after long-term consumption of calcium and dairy products, whereas, long-term intake of cream probably could increase cIMT as well as the consumptions of dairy and non-dairy products might raise the components of MetS including TG and DBP as the current study found. Thus far, because there are conflicting conclusions between these evidence, and there has not been illustrated the effect of long-term intake of calcium supplements on cardiovascular causes yet (36), it could be due to the differences between the source of calcium intake.

On the other hand, there are some cross-sectional studies related to the linkage of calcium and dairy consumption with CVD risk factors needing to be mentioned. Although, we observed no long-term 
relationship of dairy and non-dairy calcium intake with MetS in our findings, we have previously observed that low-fat dairy products reduced risk of MetS in children and adolescents of the same population (TLGS) (37). Moreover, in another study, adults showed that higher calcium intake could diminish the risk of CVD only in women (38). With regard to food pattern changes, the Bogalusa Heart Study indicated that from childhood to adulthood, there was a decrease in consumption of milk, especially in males (39). It seems that adults are more likely to adhere to unhealthy dietary patterns than children as we also observed that adolescents had higher intake of dairy and total calcium in comparison with adults. Besides, in adults, it was observed that the intake of low-fat dairy had association with reduced PWV and cIMT (40). Although, cheese and milk consumption did not have the relationship with cIMT, $100 \mathrm{~g}$ yoghurt/d could lower cIMT in elderly women (41). In contrast, it was seen that calcium consumption with supplements resulted in escalated cIMT in postmenopausal women with dyslipidemia (11). Overall, observing cross-sectional evidence seemed like that adulthood intake of calcium from dairy sources can reduce cIMT and other CVD risks.

The reason that there has not been the link between calcium intake and cardiovascular risks after a long time might be the independent role of circulating calcium levels from the sources of supplements, although it was claimed that circulating calcium can lead to artery calcification and clotting (10). In the current study, we evaluated this relationship in young adults which may be early to observe plaques and therefore increased cIMT, notwithstanding elevated cIMT and performing plaques can happen in early stage of life (42). Hence, calcium deposition has not been caused by the intake of dietary calcium and dairy products. It is worth mentioning that calcium begins its protective and lifelong role in cardiovascular risk factors from early in life so that it is necessary to consider diet from childhood to prevent them from chronic diseases in adulthood. Another hypothesis related to the influence of dairy products on artery structure is about lipid content of this product, in particular saturated fatty acid (SFA) having association with many negative health effects which may cause increased LDL levels, and thus an increased risk of CVD (43). Regarding this, we could observe the high consumption of cream consisting of SFA associated with elevated cIMT (44). However, findings have indicated that the link between SFA and CVD could not be considered evident than previously assumed due to the different combination of foods in saturated and unsaturated fatty acids, as well as contribution of significant quantities of other nutrients such as potassium and magnesium that may alter CVD risk (45).

The present study had some strength needing to be mentioned. First, it had a cohort design in which we observed the tracking intake of calcium and dairy products from adolescence to adulthood. Secondly, it was considered both cIMT and MetS which are strong risk factors for CVD since childhood and adolescence. Also, it is prominent to interpret the study in the light of limitations. We could only regard young adults as their cIMT were measured and this period of time is early to observe increased cIMT. Also, 10 years of follow-up was a short-term for observing the changes of artery structure. We did not consider other source of calcium as supplements that my change the results. Furthermore, changes the diet and food items during 10 years should have considered as it might affect the outcomes. 


\section{Conclusions}

Adolescence calcium and dairy products could not lead to increased cIMT and MetS in early adulthood. Although, it is suggested that cream should be consumed with caution. Moreover, long-term intake of total calcium, non-dairy, and skim milk could increase TG and DBP in young adults.

\section{Abbreviations}

BMI, Body Mass index; CVD, Cardiovascular disease; CIMT, carotid intima media thickness; CHD, coronary heart disease; DBP, diastolic blood pressure; FBS, fasting blood sugar; FCT, food composition table; FFQ, Food Frequency Questionnaire; HDL, high-density lipoprotein; ICC, interclass correlation coefficient; JIS, joint interim statement; LCCA, left common carotid artery; LRC, Lipid Research Clinics; LDL, low-density lipoprotein; MetS, Metabolic syndrome; MAQ, Modifiable Activity Questionnaire; PWV, pulse wave velocity; SFA, saturated fatty acid; SBP, systolic blood pressure; TLGS, Tehran Lipid and Glucose Study; TG, triglyceride; USDA, United States Department of Agriculture; WC, Waist circumference.

\section{Declarations}

\section{Ethics approval and consent to participate}

The ethics research council of the Research Institute for Endocrine Sciences, Shahid Beheshti University of Medical Sciences approved the protocol of this study and all participants provided written consent.

\section{Consent for publication}

Not applicable

\section{Availability of data and materials}

The datasets used and/or analysed during the current study are available from the corresponding author on reasonable request.

\section{Competing interests}

The authors have no conflicts of interest relevant to this article to disclose.

\section{Funding}

No external funding for this manuscript.

\section{Authors' contributions}


Assa AkbarySedigh and Golaleh Asghari conceptualized and designed the study, interpreted the data, prepared the manuscript and approved the final manuscript as submitted. Maryam Mahdavi analyzed the data, drafted the initial manuscript, and approved the final manuscript as submitted. Parvin Mirmiran and Fereidoun Azizi supervised the project, drafted the initial manuscript, and approved the final manuscript as submitted.

\section{Acknowledgments}

The authors express their appreciation to the participants in the Tehran Lipid and Glucose Study for their enthusiastic support, and the staff of the Tehran Lipid and Glucose Study Unit of the Research Institute for Endocrine Sciences, for their valuable help. We wish to thank Maryam Mahdavi for analyzing the data, drafting the initial manuscript, and approving the final manuscript as submitted. We also thank Parvin Mirmiran and Fereidoun Azizi for supervising the project, drafting the initial manuscript, and approving the final manuscript as submitted.

\section{References}

1. Ahmadi-Abhari S, Sabia S, Shipley MJ, Kivimäki M, Singh-Manoux A, Tabak A, et al. Physical activity, sedentary behavior, and long-term changes in aortic stiffness: the Whitehall II study. Journal of the American Heart Association. 2017;6(8):e005974.

2. Mansourian M, Babahajiani M, Jafari-Koshki T, Roohafza H, Sadeghi M, Sarrafzadegan N. Metabolic syndrome components and long-term incidence of cardiovascular disease in Eastern Mediterranean region: a 13-year population-based cohort study. Metab Syndr Relat Disord. 2019;17(7):362-6.

3. Nettleton JA, Polak JF, Tracy R, Burke GL, Jacobs DR Jr. Dietary patterns and incident cardiovascular disease in the Multi-Ethnic Study of Atherosclerosis. Am J Clin Nutr. 2009;90(3):647-54.

4. Palombo C, Kozakova M. Arterial stiffness, atherosclerosis and cardiovascular risk: pathophysiologic mechanisms and emerging clinical indications. Vascul Pharmacol. 2016;77:1-7.

5. Kastorini C-M, Milionis HJ, Esposito K, Giugliano D, Goudevenos JA, Panagiotakos DB. The effect of Mediterranean diet on metabolic syndrome and its components: a meta-analysis of 50 studies and 534,906 individuals. Journal of the American college of cardiology. 2011;57(11):1299-313.

6. Djousse L, Padilla H, Nelson T, Gaziano J, Mukamal K. Diet and metabolic syndrome. Endocrine, Metabolic \& Immune Disorders-Drug Targets (Formerly Current Drug Targets-Immune. Endocrine Metabolic Disorders). 2010;10(2):124-37.

7. Alissa EM, Helmi SR, Maisa'a M. Relationship between diet quality and carotid intima-media thickness in people with and without carotid atherosclerosis. Journal of family medicine primary care. 2018;7(3):531.

8. Cao Y, Wang C, Guan K, Xu Y, Su Y-x, Chen Y-m. Association of magnesium in serum and urine with carotid intima-media thickness and serum lipids in middle-aged and elderly Chinese: a community- 
based cross-sectional study. Eur J Nutr. 2016;55(1):219-26.

9. Hosseini B, Saedisomeolia A, Skilton MR. Association between micronutrients intake/status and carotid intima media thickness: a systematic review. Journal of the Academy of Nutrition Dietetics. 2017; 117(1):69-82.

10. Reid IR, Birstow SM, Bolland MJ. Calcium and cardiovascular disease. Endocrinology metabolism. 2017;32(3):339.

11. Li S, Na L, Li Y, Gong L, Yuan F, Niu Y, et al. Long-term calcium supplementation may have adverse effects on serum cholesterol and carotid intima-media thickness in postmenopausal women: a double-blind, randomized, placebo-controlled trial. Am J Clin Nutr. 2013;98(5):1353-9.

12. Wu F, Pahkala K, Juonala M, Rovio SP, Sabin MA, Rönnemaa T, et al. Childhood and long-term dietary calcium intake and adult cardiovascular risk in a population with high calcium intake. Clin Nutr. 2021;40(4):1926-31.

13. Bhupathi V, Mazariegos M, Rodriguez JBC, Deoker A. Dairy intake and risk of cardiovascular disease. Curr Cardiol Rep. 2020;22(3):1-6.

14. Alexander DD, Bylsma LC, Vargas AJ, Cohen SS, Doucette A, Mohamed M, et al. Dairy consumption and CVD: a systematic review and meta-analysis. Br J Nutr. 2016;115(4):737-50.

15. Lordan R, Tsoupras A, Mitra B, Zabetakis I. Dairy fats and cardiovascular disease: do we really need to be concerned? Foods. 2018;7(3):29.

16. Michaëlsson K, Melhus H, Lemming EW, Wolk A, Byberg L. Long term calcium intake and rates of all cause and cardiovascular mortality: community based prospective longitudinal cohort study. Bmj. 2013;346.

17. Bolland MJ, Avenell A, Baron JA, Grey A, MacLennan GS, Gamble GD, et al. Effect of calcium supplements on risk of myocardial infarction and cardiovascular events: meta-analysis. Bmj. 2010;341:c3691.

18. Wang X, Chen H, Ouyang Y, Liu J, Zhao G, Bao W, et al. Dietary calcium intake and mortality risk from cardiovascular disease and all causes: a meta-analysis of prospective cohort studies. BMC Med. 2014;12(1):1-10.

19. Azizi F, Madjid M, Rahmani M, Emami H, Mirmiran P, Hadjipour R. Tehran Lipid and Glucose Study (TLGS): rationale and design. Iranian journal of endocrinology metabolism. 2000;2(2):77-86.

20. Mirmiran P, Esfahani FH, Mehrabi Y, Hedayati M, Azizi F. Reliability and relative validity of an FFQ for nutrients in the Tehran lipid and glucose study. Public Health Nutr. 2010;13(5):654-62.

21. Momenan AA, Delshad M, Sarbazi N, REZAEI GN, Ghanbarian A, AZIZI F. Reliability and validity of the Modifiable Activity Questionnaire (MAQ) in an Iranian urban adult population. 2012.

22. Ainsworth BE, Jacobs DR Jr, Leon AS. Validity and reliability of self-reported physical activity status: the Lipid Research Clinics questionnaire. Med Sci sports Exerc. 1993;25(1):92-8.

23. Azizi F, Ghanbarian A, Momenan AA, Hadaegh F, Mirmiran P, Hedayati M, et al. Prevention of noncommunicable disease in a population in nutrition transition: Tehran Lipid and Glucose Study phase 
II. Trials. 2009;10(1):1-15.

24. Tasdighi E, Barzin M, Mahdavi M, Valizadeh M, Dehghan P, Moghaddam AM, et al. Association of childhood obesity phenotypes with early adulthood carotid intima-media thickness; Tehran Lipid and Glucose Study. Nutrition, Metabolism and Cardiovascular Diseases; 2021.

25. Asghari G, Dehghan P, Mirmiran P, Yuzbashian E, Mahdavi M, Tohidi M, et al. Insulin metabolism markers are predictors of subclinical atherosclerosis among overweight and obese children and adolescents. BMC Pediatr. 2018;18(1):1-8.

26. Cook S, Weitzman M, Auinger P, Nguyen M, Dietz WH. Prevalence of a metabolic syndrome phenotype in adolescents: findings from the third National Health and Nutrition Examination Survey, 1988-1994. Arch Pediatr Adolesc Med. 2003;157(8):821-7.

27. Kelishadi R, Gouya MM, Ardalan G, Hosseini M, Motaghian M, Delavari A, et al. First reference curves of waist and hip circumferences in an Asian population of youths: CASPIAN study. J Trop Pediatr. 2007;53(3):158-64.

28. Pediatrics AAo. National high blood pressure education program working group on high blood pressure in children and adolescents. Pediatrics. 2004;114(Supplement 2):iv-v.

29. Genuth S, Alberti K, Bennett P, Buse J, Defronzo R, Kahn R, et al. Expert Committee on the Diagnosis and Classification of Diabetes Mellitus-American Diabetes Association. Follow-up report on the diagnosis of diabetes mellitus. Diabetes Care. 2003;26:3160-7.

30. Alberti K, Eckel RH, Grundy SM, Zimmet PZ, Cleeman JI, Donato KA, et al. Harmonizing the metabolic syndrome: a joint interim statement of the international diabetes federation task force on epidemiology and prevention; national heart, lung, and blood institute; American heart association; world heart federation; international atherosclerosis society; and international association for the study of obesity. Circulation. 2009;120(16):1640-5.

31. Delavari A, Forouzanfar MH, Alikhani S, Sharifian A, Kelishadi R. First nationwide study of the prevalence of the metabolic syndrome and optimal cutoff points of waist circumference in the Middle East: the national survey of risk factors for noncommunicable diseases of Iran. Diabetes Care. 2009;32(6):1092-7.

32. Van der Pols J, Gunnell D, Williams G, Holly J, Bain C, Martin R. Childhood dairy and calcium intake and cardiovascular mortality in adulthood: 65-year follow-up of the Boyd Orr cohort. Heart. 2009;95(19):1600-6.

33. Sun X, Shi Z, Li Y, Xin B, Li X, Wang Y. U-shaped association between dietary calcium density intake during adolescence and hypertension in adulthood: a 20-year longitudinal nationwide study in China. British Journal of Nutrition. 2021:1-8.

34. Wu F, Juonala M, Pahkala K, Buscot M-J, Sabin MA, Pitkänen N, et al. Youth and long-term dietary calcium intake with risk of impaired glucose metabolism and type 2 diabetes in adulthood. The Journal of Clinical Endocrinology Metabolism. 2019;104(6):2067-74.

35. Malik VS, Sun Q, van Dam RM, Rimm EB, Willett WC, Rosner B, et al. Adolescent dairy product consumption and risk of type 2 diabetes in middle-aged women-. Am J Clin Nutr. 2011;94(3):854- 
61.

36. Hsia J, Heiss G, Ren H, Allison M, Dolan NC, Greenland P, et al. Calcium/vitamin D supplementation and cardiovascular events. Circulation. 2007;115(7):846-54.

37. Yuzbashian E, Nosrati-Oskouie M, Asghari G, Chan CB, Mirmiran P, Azizi F. Associations of dairy intake with risk of incident metabolic syndrome in children and adolescents: Tehran Lipid and Glucose Study. Acta Diabetol. 2021;58(4):447-57.

38. Kong SH, Kim JH, Hong AR, Cho NH, Shin CS. Dietary calcium intake and risk of cardiovascular disease, stroke, and fracture in a population with low calcium intake. Am J Clin Nutr. 2017;106(1):27-34.

39. Demory-Luce D, Morales M, Nicklas T, Baranowski T, Zakeri I, Berenson G. Changes in food group consumption patterns from childhood to young adulthood: the Bogalusa Heart Study. J Am Diet Assoc. 2004;104(11):1684-91.

40. Recio-Rodriguez JI, Gomez-Marcos MA, Patino-Alonso M-C, Sanchez A, Agudo-Conde C, MaderueloFernandez JA, et al. Association between fat amount of dairy products with pulse wave velocity and carotid intima-media thickness in adults. Nutrition journal. 2014;13(1):1-5.

41. Ivey KL, Lewis JR, Hodgson JM, Zhu K, Dhaliwal SS, Thompson PL, et al. Association between yogurt, milk, and cheese consumption and common carotid artery intima-media thickness and cardiovascular disease risk factors in elderly women. Am J Clin Nutr. 2011;94(1):234-9.

42. Jourdan C, Wühl E, Litwin M, Fahr K, Trelewicz J, Jobs K, et al. Normative values for intima-media thickness and distensibility of large arteries in healthy adolescents. J Hypertens. 2005;23(9):170715.

43. Artaud-Wild SM, Connor S, Sexton G, Connor W. Differences in coronary mortality can be explained by differences in cholesterol and saturated fat intakes in 40 countries but not in France and Finland. A paradox. Circulation. 1993;88(6):2771-9.

44. Aviram M, Brox J, Nordoy A. Acute effects of dietary cod liver oil and cream on plasma lipoproteins. Annals of nutrition metabolism. 1986;30(2):143-8.

45. Huth PJ, Park KM. Influence of dairy product and milk fat consumption on cardiovascular disease risk: a review of the evidence. Advances in nutrition. 2012;3(3):266-85.

\section{Supplementary Files}

This is a list of supplementary files associated with this preprint. Click to download.

- SupplementTables.docx 